\title{
How Compliant are Beverage Employees to Occupational Health and Safety Regulations?
}

\begin{abstract}
This observational study was undertaken to identify the health and safety violations of employees at a specific beverage manufacturing company. A site inspection and observation of all employees employed at this specific beverage company was conducted by the researcher over 2 days. Employees were observed for 12 hours per day with the morning shift on Day 1 and the afternoon shift on Day 2. A sample of convenience was used in that every employee who was present on those days was included. Descriptive statistics were used to analyze the data set. There were a total of 212 employees and 332 behaviours observed during this study period. Unsafe handling and behaviour was observed in 55\% of observations. Incorrect manual lifting techniques was the most frequent health and safety violation observed. In the 48 manual lifting behaviours observed, correct practice was observed in only three cases. It is clear that more healthcare education and practical training is required in the area of manual lifting techniques. It is clear that more practical training is required in the area of manual handling.

\section{Chetty L, MSc(Phys)'; Jelsma J, PhD'; Maart S MPH, BSc(Phys) ${ }^{3}$}

1 Senior Physiotherapist, Injury Prevention and

Rehabilitation Services, United Kingdom.

2 Professor, University of Cape Town, Faculty of Health Sciences, Division of

Physiotherapy, South Africa.

3 Senior Lecturer, University of Cape Town, Faculty of Health Sciences, Division of Physiotherapy, South Africa.
\end{abstract}

KEYWORDS: OCCUPATIONAL HEALTH AND SAFETY, BEVERAGE EMPLOYEES, SITE INSPECTION, OBSERVATION, COMPLIANCE.

\section{INTRODUCTION}

Accurate observations of occupational activities are necessary to monitor health and safety compliance and to identify the interventions that are most needed (Pransky et al., 1999). With rapid advances in technology, employees are now increasingly subjected to the exposure of more dangerous newly developed machinery and undue psychological stressors (Furlow, 2002). Several studies (Bentley et al., 2005; Laurence, 2005; Shrader-Frechettek and Cooke, 2004) have indicated that these advances have resulted in many companies facing an increasing number of health and safety violations amongst the workforce. Some of these violations include a lack of personal protective equipment, using incorrect hand postures and the improper use of

\section{Correspondence to:}

Laran Chetty

Injury Prevention and

Rehabilitation Services,

United Kingdom

Email: laranchetty@yahoo.com machinery (Torp et al., 2005; Wilson, 2005), amongst others. There is still little liaison by physiotherapists with other health related professionals, poor formal risk assessments measuring health and safety compliance and poor integration of relevant role players into the management of health and safety violations (Ehrens, 2001). As physiotherapists have a pivotal role to play in occupational health and ergonomics this lack of interdisciplinary intervention will impact poorly on the workers health.

The company under investigation was an alcohol beverage manufacturing company. The medical service co-ordinator is responsible for the implementation and control of the occupational health facet. The aims are to identify those processes, chemical substances or types of work that could negatively impact on a workers' health and to eliminate, minimise or control the hazard. The occupational health programme at this company is compliant with the extent of the Occupation Health and Safety Act of 1993 that requires occupational health risk areas, jobs, processes, hazardous substances etc., to be iden- tified, assessed, quantified and appropriate measures to be developed and implemented. The identification and assessment of occupational health risks are carried out via the Risk Management Programme (RMP). Consultants are used from time to time to assess the risk or to assist the company in setting up the methodology so that occupational health personnel can carry out the necessary tasks to assess the injury.

Although this company is committed in its moral and legal obligations to ensuring a working environment that is safe and free from hazards [personal communication], the extent of compliance of employees regarding health and safety regulations has not been established at this specific company.

The purpose of this present study was therefore to monitor the compliance of employees regarding health and safety regulations by observing their activities and noting how many and what violations took place over that period of time.

\section{METHODS}

This study received ethical clearance from the University of Cape Town 
Ethics Committee. To ensure that workers were committed to taking part in the study, permission to conduct this study was obtained from both senior management and the employees' union representatives at this specific beverage company. Although employees were informed that they will be observed for the purpose of this study, they were not informed of the actual dates of observation in order to prevent them from performing better simply because they are being watched.

A site inspection and observation of all employees employed at this specific beverage manufacturing company was conducted by the researcher over 2 non-consecutive days. Employees were observed for 12 hours per day with the morning shift on Day 1 and the afternoon shift on Day 2. A sample of convenience was used in that every employee who was present on those days was included.

Employees were monitored for their compliance with health and safety protocols and procedures. The researcher used a checklist which was based on the General Safety Rules and Guidelines section of the health, safety and risk control manual at this specific company. Face validity was assumed as the checklist was based on the occupational health, safety and risk training manual utilsed by the company. Content validity of the checklist was addressed as input from experts in physiotherapy research and occupational health were consulted to scrutinise a draft copy. This checklist was used to note how many and what health and safety violations took place over that period. This was calculated as the number of violations per employee present at the time. This checklist included 10 main categories and 34 sub-categories. The data from the checklist was reduced to percentages and analysed descriptively using the Statistica 7 package. The level of significance was set at 0.05 .

\section{RESULTS}

There were a total of 212 employees and 332 behaviours observed during this study period. Table 1 lists the number of times tasks were observed and whether or not they were correctly performed. It can be seen that in $55.4 \%$ of cases standard procedure was not followed.

\section{Good Housekeeping}

Eighty health and safety behaviours ( $24.1 \%$ of total) were observed for this task. Of these, on twenty-five occasions $(31.3 \%)$ employees were observed to have correctly placed their waste and general rubbish in the bins provided. On ten occasions $(12.5 \%)$ employees removed excessive combustibles from the working area. On twenty-six occasions $(32.5 \%)$ employees were observed to have stored items in the incorrect boxes/lockers and on two occasions (2.5\%) employees were observed to have inadequately cleaned spilled chemicals on the floor.

\section{Stacking and Storage}

Thirty-three health and safety behaviours (9.9\% of total) were observed for this task. In response to this task, it was noted on seven occasions $(21.2 \%)$ that employees correctly stored dangerous goods. On fourteen occasions (14.2\%) it was noted that employees correctly kept roadways between the stacks clear. A site inspection of the workshop floor revealed that on four occasions $(1.2 \%)$ the fire and electrical equipment was stored within easy access.

\section{Walkways}

Twenty-six health and safety behaviours (7.8\% of total) were observed for this task. On fourteen occasions $(53.8 \%)$ employees were observed to have correctly followed the demarcated walkways throughout the depot. On further inspection, it was observed that three walkways were obstructed with working tools. However, of the five employees that used these walkways, only four employees removed the working tools that obstructed these walkways.

\section{Fire Protection, Prevention and Emer- gency Response}

Thirty-seven health and safety behaviours (11.8\% of total) were observed for this task and then employees were questioned in order to elicit a response on the knowledge of fire safety. It was noted that four employees $(10.8 \%)$ knew the correct type of fire extinguishers to use, five employees (16.5\%) could adequately identify the location of all fire extinguishers and six employees (1.8\%) knew how to correctly mount the fire extinguishers. However, on thirteen occasions (31.1\%) employees were observed not to have correctly followed the symbols/signs demarcating danger when they entered dangerous work zones.

\section{Safety Devices (SDs) and Personal Protective Equipment (PPE)}

Thirty-seven health and safety behaviours $(11.1 \%$ of total) were observed for this task. Employees were observed on four occasions (10.8\%) to have incorrectly stored SDs. On ten occasions (27\%) employees were observed not to have issued the correct SD and/or any PPE when required. On only one occasion $(2.7 \%)$ did a employee seek permission prior to tampering with or removing a SD. On eight occasions (21.6\%) employees were observed to have correctly used the SDs and PPE.

\section{Hand Tools}

Twenty-eight health and safety behaviours $(8.4 \%$ of total) were observed for this task. On six occasions (14.3\%) employees did not use hand tools that were in a good working condition, on four occasions $(14.3 \%)$ employees did not store them in the correct toolbox, while on two occasions (7.1\%) employees used the correct work-specific tools. On eleven occasions (39.3\%) employees did not apply correct hand postures when using their tools.

\section{Work Area}

Thirteen health and safety behaviours (3.9\% of total) were observed for this task. With regards to the working area, on two occasions (15.4\%) employees correctly removed all obstacles, on four occasions (30.8\%) employees ensured that there was good lighting while on three occasions employees worked in areas with adequate ventilation.

\section{Manual Lifting Techniques}

Forty-eight health and safety behaviours (14.5\% of total) were observed for this task. In twenty-two cases (45.8\%) employees were observed to have used 
Table 1: Checklist depicting the number of health and safety violations observed

\begin{tabular}{|c|c|c|c|}
\hline TASK & $\begin{array}{l}\text { Behaviour } \\
\text { observed }\end{array}$ & $\begin{array}{l}\text { Correctly } \\
\text { done }\end{array}$ & $\begin{array}{l}\text { Incorrectly } \\
\text { done }\end{array}$ \\
\hline \multicolumn{4}{|l|}{ 1. Good Housingkeeping } \\
\hline 1.1 Waste and general rubbish placed in bins provided & 27 & 25 & 2 \\
\hline 1.2 Area kept free of excessive combustibles & 13 & 10 & 3 \\
\hline 1.3 Items stored in correct boxes/lockers & 38 & 12 & 26 \\
\hline 1.4 Chemicals spilled on floor adequately cleaned & 2 & 0 & 2 \\
\hline \multicolumn{4}{|l|}{ 2. Stacking and Storage } \\
\hline 2.1 Dangerous goods stored correctly & 9 & 7 & 2 \\
\hline 2.2 Roadways between stacks kept clear & 17 & 14 & 3 \\
\hline 2.3 Fire and electrical equipment easily accessible & 7 & 3 & 4 \\
\hline \multicolumn{4}{|l|}{ 3. Walkways } \\
\hline 3.1 Following demarcated walkways throughout the depot & 21 & 14 & 7 \\
\hline 3.2 Walkways clear and unobstructed & 5 & 4 & 1 \\
\hline \multicolumn{4}{|l|}{ 4. Fire Protection, Prevention and Emergency Response } \\
\hline 4.1 Correct type of fire extinguishers for hazard & 6 & 4 & 2 \\
\hline 4.2 Adequate number of fire extinguishers & 6 & 5 & 1 \\
\hline 4.3 Fire extinguishers mounted correctly & 6 & 6 & 0 \\
\hline 4.4 Staff following symbolic signs/notices demarcating danger & 19 & 6 & 13 \\
\hline \multicolumn{4}{|l|}{ 5. Safety Devices (SD) \& Personal Protective Equipment (PPE) } \\
\hline 5.1 Safety devices correctly stored & 7 & 3 & 4 \\
\hline 5.2 PPE issued (when necessary) & 13 & 3 & 10 \\
\hline 5.3 Authorised tampering or removal of safety devices & 1 & 1 & 0 \\
\hline 5.4 Defective SD and PPE reported to supervisor & 3 & 3 & 0 \\
\hline 5.5 Correct use of SD and PPE & 13 & 8 & 5 \\
\hline \multicolumn{4}{|l|}{ 6. Hand Tools } \\
\hline 6.1 In good condition & 9 & 3 & 6 \\
\hline 6.2 Correctly stored in toolbox & 5 & 1 & 4 \\
\hline 6.3 Work-specific tools used & 3 & 2 & 1 \\
\hline 6.4 Correct hand ergonomics when using tools & 11 & 0 & 11 \\
\hline \multicolumn{4}{|l|}{ 7. Work Area } \\
\hline 7.1 Obstacles removed & 3 & 2 & 1 \\
\hline 7.2 Area well lit & 5 & 4 & 1 \\
\hline 7.3 Adequate ventilation & 5 & 3 & 2 \\
\hline \multicolumn{4}{|l|}{ 8. Manual Lifting Techniques } \\
\hline 8.1 Using manual lifting techniques & 22 & 0 & 22 \\
\hline 8.2 Asking for additional help when lifting heavy objects & 22 & 3 & 19 \\
\hline 8.3 Seeking authorisation when using lifting equipment & 4 & 0 & 4 \\
\hline \multicolumn{4}{|l|}{ 9. Incident Reporting } \\
\hline 9.1 Reporting incidents/injuries to supervisor & 3 & 0 & 3 \\
\hline 9.2 Reporting nature of incident & 3 & 0 & 3 \\
\hline 9.3 Reporting cause of injury & 3 & 0 & 3 \\
\hline \multicolumn{4}{|l|}{ 10. General Safety } \\
\hline 10.1 Visitors given consent form to sign before entering premises & 7 & 0 & 7 \\
\hline 10.2 Staff checking visitors' temporary identification card & 7 & 0 & 7 \\
\hline 10.3 Visitors issued with PPE (when necessary) & 7 & 2 & 5 \\
\hline Total & $\begin{array}{l}332 \\
(100 \%)\end{array}$ & $\begin{array}{l}148 \\
(44.6 \%)\end{array}$ & $\begin{array}{l}184 \\
(55.4 \%)\end{array}$ \\
\hline
\end{tabular}

incorrect manual handling techniques. In an additional 25 cases where the object was very heavy, on only three occasions (6.3\%) did employees ask for additional help. On four occasions $(8.3 \%)$ it was noted that employees did not seek authorization prior to using lifting equipment.
Incident Reporting

Nine health and safety behaviours (2.7\% of total) were observed for this task following on occupational hand- 
tool injury at the company. The three employees present at the time of the incident incorrectly reported the injury to the supervisor, the same three employees incorrectly reported the nature of the injury and the same three employees incorrectly reported the cause of the injury.

\section{General Safety}

This section describes the behaviour related to visitors at the company. Twenty-one health and safety behaviours (6.3\% of total) were observed for this task. With regards to general safety it was observed on seven occasions that visitors were not given consent forms to sign before entering the premises, while on seven occasions it was noted that no employee checked the temporary identification cards of these visitors and on only two occasions were visitors given the correct personal protective equipment when required.

\section{DISCUSSION}

The site inspection and observation of the working environment provided the researcher with valuable information about the compliance of beverage employees regarding health and safety regulations. Employees from all departments were observed to give a spread of the health and safety compliance at this specific beverage manufacturing company. There was a high incidence $(56 \%)$ of safety violations observed in this study, which has similarly been reported in other studies (Afamdi, 2001; Cherry et al., 2001; Di Lorenzo et al., 1998; Gleeson, 2001; Hollo et al., 1993; Li et al., 2001).

Most of the employees maintained a clean working environment and their specific work areas were kept relatively clear of any obstructions. However, the majority of employees did not return the items used to their correct boxes/ lockers. This may have serious repercussions in that the tools and spares left about may cause other employees to trip-and-fall (Cham and Redfern, 2001; Englander et al., 1996; Jenson et al., 2005) contributing to injury. Good housekeeping is the responsibility of every employee and a clean working environment is indicative of a successful health and safety programme.

Most of the employees correctly stacked dangerous goods and kept the roadways between these stacks clear. This is an encouraging sign towards health and safety compliance, as the accumulation of dangerous goods may block the roadways leading to potentially hazardous obstructions. Care must also be taken to ensure that on no occasion should the stacks encroach onto the roadways. Similar to other studies (Berrios-Torres et al., 2003; Prezant et al., 2000; Rabbitts et al., 2005) most employees did not ensure that the fire and electrical equipment was stored within easy access. This may be considered negligent as in the event of a fire or electrical accident many lives could be lost.

It was observed that the walkways at this specific beverage company were demarcated throughout the depots. Most of the employees observed did follow the demarcated signs and ensured that these walkways were clear and unobstructed. It is suggested that employees also become familiar with the safest route to and from their working station as shortcuts can be dangerous.

Most of the employees could correctly use and mount the fire extinguishers. It was observed that the majority did not follow the symbolic signs/notices demarcating danger It is possible that most employees did not understand the symbolic signs/notices warning them of potentially dangerous situations and/or areas. It is suggested that another system of communication be used to ensure that employees are able to identify any dangerous or restricted areas. A colour coding system was mentioned in other studies (Boult, 2000; Chervin and Bodman, 2004; Leonelli et al., 2000) as a means of identifying the contents of dangerous pipelines, sharp containers, demarcated areas etc.

The majority of employees did not correctly store or issue PPE when required. PPE must be issued to all employees and visitors who are exposed to areas in which hazards cannot be totally removed (Galszechy, 1999). In addition, since every employee has different size requirements it is recommended that a selection of PPE be made available. On a more positive side, most employees who did use SDs and/ or issued PPE were observed to have used them correctly.

Most of the employees used hand tools that were in a poor condition. As with other studies (Aptel et al., 2002; Lin et al., 2005) employees did not use correct hand postures when using their hand tools. Employees must ensure that their hand tools are always in a good working condition and correctly stored in the toolboxes. It is recommended that the supervisor check condition of the hand tools on a regular basis and record any defects in the safety file. Defective hand tools are potential causes for accidents and injuries.

The office working area was kept relatively free of any obstacles. It was observed that on most occasions employees worked in areas that were well lit and adequately ventilated. Good ventilation and good lighting are important to ensure the health, safety and efficiency of employees.

As with other studies (Carrivick et al., 2005; Engkvist, 2005) the majority of employees were observed to have used incorrect manual lifting techniques. In addition, most employees did not ask for additional help when lifting heavy objects or sought authorization when using lifting equipment. The incorrect lifting techniques can result in excessive strain being place on the lower back (Glover, 2002). Occupational physiotherapists can provide practical training shifts on correct lifting techniques. In addition, employees must be encouraged to ask for additional help when lifting heavy objects.

The majority of employees were observed to have incorrectly reported the cause and nature of injury to their supervisor. It is possible that these employees believed that the injury sustained was minor and did not warrant being fully reported. The onus is on the employee to correctly report the injury to the supervisor before the end of the shift no matter how minor the injury may seem at the time.

At this specific beverage company all visitors are expected to pass through Security Control (Gate 2) in order to register their access to and from the 
company. It was observed that most of the visitors were not given consent forms to sign before they entered the working premises nor were they issued with the correct PPE when required. The health and safety of visitors is the responsibility of the company, as visitors may go into unfamiliar places where they could endanger their lives. It is suggested that visitors be escorted to their destination within the company and be supplied with the correct PPE when taken into areas where such equipment is warranted.

The major limitation of the study is the lack of objective measures of unsafe behaviour and lack of compliance with safety standards. As it was an observational study, it was important that the observer be as unobtrusive as possible and the decisions as to what constituted unsafe behaviour were therefore subjective. In the absence of video-recording and peer review, these decisions are not necessarily without bias. However, as a physiotherapist is trained to visually assess movement and ergonomically correct behaviour, it is hoped that the information recorded is of an adequate standard to inform future practice within this setting.

\section{CONCLUSION}

Workers demonstrated poor adherence to safety practices with unsafe and incorrect behaviour observed in $55 \%$ of observations. Incorrect manual lifting techniques was the most frequent health and safety violation observed. In the 48 manual lifting behaviours observed, correct practice was observed in only three cases. It is clear that more healthcare education and practical training is required in the area of manual lifting techniques.

With occupational health fast becoming a growing field in the physiotherapy profession, physiotherapists must respond positively to the challenge of identifying those factors that contribute to injuries in the workplace. We need to demonstrate our effectiveness in this area in order to promote quality of care and to protect and educate employees on taking a more proactive role of becoming compliant to the regulations that govern occupation health in this country. This study has clearly demonstrated the need for better education in health related work behavior, particularly in the field of kinetic handling.

\section{REFERENCES}

Afamdi O 2001 A study of fatal injuries in Nigerian factories. Occupational Medicine 51: 485-489

Aptel M, Claudon L, Marsot J 2002 Integration of ergonomics into hand tool design: principle and presentation of an example. International Journal of Occupational Safety Ergonomics 8(1): 107-115

Bentley TA, Parker KJ, Ashby L 2005 Understanding falling safety in the New Zealand forest company. Applied Ergonomics 36(2): 165-175

Berrios-Torres SI, Greenko JA, Phillips M, Miller JR, Treadwell T, Ikeda RM 2003 World Trade Centre rescue employee injury and illness surveillance, New York, 2001. American Journal of Preventative Medicine 25(2): 79-87

Boult M 2000 Risk management of LPG transport activities in Hong Kong. Journal of Hazardous Materials 71(1-3): 85-100

Carrivick PI, Lee AH, Yau KK, Stevenson MR 2005 Evaluating the effectiveness of a participatory ergonomics approach in reducing the risk and severity of injuries from manual handling. Ergonomics 48(8): 907-914

Cham R, Redfern MS 2001 Lower extremity corrective reactions to slip events. Journal of Biomechanics 34(11): 1439-1445

Cherry NM, Meyer JD, Chen Y, Holt DL, McDonald JC The reported incidence of occupational musculoskeletal injury in the UK: MOSS 1997-2000. Journal of Occupational Medicine 51: 450-455

Chervin S, Bodman GT 2004 Testing strategy for classifying self-heating substances for transport of dangerous goods. Journal of Hazardous Materials 115(1-3): 107-110

Di Lorenzo L, Zocchetti C, Platania A, De Francesco G, De Metrio R, Pirris A, Gigante MR 1998 Minor and major work accidents in a Puglia business in the food sector: a 10-year study. Journal of Medicine 89(6): 499-513

Engkvist IL 2005 Evaluation of an intervention comprising a no lift policy in Australian hospitals. Applied Ergonomics (no page numbers available)

Englander F, Hodson TI, Terregrossa RA 1996 Ergonomic dimensions of slip and fall injuries. Journal of Forensic Science 41(5): 733-746

Ehrens A 2001 Physiotherapy and risk management. Physioforum, March:10-12

Furlow B 2002 Ergonomics in the healthcare environment. Radiology Technology 72(2): $137-150$
Galszechy T 1999 The effects of vibration on hands and arms: clinical brief. Journal of the American Association of Occupational Health Nursing 47(3): 117-119

Gleeson D 2001 Health and safety in the catering company. Journal of Occupational Medicine 51: 385-391

Glover W 2002 Occupational strain injuries in physiotherapists. Physiotherapy 88(6): 364-372 Hollo CD, Leigh J, Nurminen M 1993 The role of alcohol in occupational fatal accidents in Australia 1982-1984. Journal of Occupational Medicine 43(1): 13-17

Jenson OC, Sorensen IF, Canals ML, Hu Y, Nikolic N, Mozer AA 2005 Non-fatal occupational injuries related to slips, trips and falls. American Journal of Industrial Medicine 47(2): 161-171

Laurence D 2005 Safety rules and regulations on mine sites - the problem and a solution. Journal of Safety Rules 36(1): 39-50

Leonelli P, Bonvicini S, Spadoni G 2000 Hazardous materials transportation: a risk analysis-based routing methodology. Journal of hazardous Materials 71(1-3): 283-300

Li CY, Chen KR, Wu CH 2001 Job stress and dissatisfaction in association with non-fatal injuries on the job in a cross-sectional sample of petrochemical employees 51: 50-55

Lin JH, Radwin R, Nembhard D 2005 Ergonomic applications of a mechanical model of the human operator in power hand tool operation. Journal of Hazardous Materials 8(1): 107-115

Pransky G, Snyder T, Dembe A, Himmelstein I 1999 Under-reporting of occupational disorders in the workplace: a case study. Ergonomics 42(1): 171-182

Prezant DJ, Freeman K, Kelly KJ, Malley KS, Karwa ML, McLaughlin MT, Hirschhorn R, Brown A 2000 Impact of a design modification in modern firefighting uniforms on burn prevention outcomes in New York City firefighters. Journal of occupational Environmental Medicine 42(8): 827-834

Rabbitts A, Alden NE, Scalabrino M, Yurt RW 2005 Outpatient firefighter burn injuries: a 3-year review. Journal of Burn Care Rehabilitation 26(4): 348-351

Shrader-Frechette K, Cooke R 2004 Ethics and choosing appropriate means to and end: problems with coal mine and nuclear workplace safety 24(1): 147-156

Torp S, Grogaard JB, Moen BG, Bratveit M 2005 The impact of social and organizational factors on employees' use of personal protective equipment: a multilevel approach. Journal of Occupational Environmental Medicine 47(8): 829-837

Wilson L 2005 All injuries cannot be prevented. Occupational Health and Safety 74(4): 74-76 